\title{
One Case of Unilateral Linear Lichen Planus Pigmentosus
}

\author{
Ru-zhi Zhang ${ }^{1}$ and Wen-yuan Zhu ${ }^{*}, 2$ \\ ${ }^{I}$ Department of Dermatology, the Third Affiliated Hospital of Suzhou University, 185 Juqian Road, Changzhou 213003, \\ China \\ ${ }^{2}$ Department of Dermatology, The First Affiliated Hospital of Nanjing Medical University, Nanjing 210029, China
}

\begin{abstract}
Linear lichen planus pigmentosus is considered as a combined type of linear lichen planus and lichen planus pigmentosus (LPP), and only 4 such cases have been reported in the dermatologic literature. We report one case of linear LPP that developed on the patient's mandibular area and the right side of the extremities. The lesions on the face presented as a dark-brown streak, which was parallel to the lower lip line. The pathological findings confirmed the diagnosis of LPP. To the best of our knowledge, this pattern of LPP has not been described before. While we are uncertain as to the cause of this patterning, we believe that it will contribute to research on the pathogenesis of LPP.
\end{abstract}

Keywords: Linear lichen planus pigmentosus, facial dermatosis, extremities.

Lichen planus pigmentosus (LPP) was first described by Bhutani et al. [1]. It appears as mottled or reticulated hyperpigmented, dark brown macules or papules on sunexposed areas and in flexural folds [2]. Linear lichen planus is a subtype of lichen planus that shows a linear distribution following Blaschko's lines [3]. Linear LPP is considered as a combined type of linear lichen planus and LPP, and there have been only a few reports of this in the dermatologic literature [4-6]. Here, we report one case of unilateral linear LPP in a 25-year-old Chinese female. The lesions developed over her mandibular area and at the distal ends of her right extremities.

\section{CLINICAL DATA}

A 25 year old female presented with a 4 year history of a progressive asymptomatic linear violaceous streak, which started on the right angle of her mouth advancing towards the median line. At the same time, one or two well-defined planar, purple, polygonal papules occurred on the dorsum of her right foot and spread gradually without any preceding erythema, and finally, these blue-black or brownish papules were arranged longitudinally. Moreover, scattered violaceous speckles were found in sites near the nail-fold of the fingers on her right hand, except the thumb. Treatment with $0.05 \%$ clobetasol propionate cream produced only slight improvement. There was no history of prolonged sun exposure or trauma at the lesion sites and no history of similar pigmentation patterns in other family members.

On examination, there was a well-defined dark brown streak parallel to and near the lower lip line, starting on the right angle of the mouth and ending close to the left angle, approximately 2-3 millimeters in width and 6 centimeters in length (Fig. 1a). A few dark porphyreous speckles clustered on the skin near the nail-fold of the fingers on her right hand,

\footnotetext{
*Address correspondence to this author at the Department of Dermatology, The First Affiliated Hospital of Nanjing Medical University, 300 Guangzhou Road, Nanjing 210029, China; Tel: 86-025-86616095;

E-mail: zhuwenyuan@yahoo.com
}

except the thumb (Fig. 1b). On the dorsum of her right foot, many flat-topped, shiny, purple and polygonal papules, ranging in size from 1 to $3 \mathrm{~mm}$, showed a distribution in a zosteriform pattern (Fig. 1c). No lesions were found on the rest of her body or on any mucosal surfaces. Routine laboratory data, including peripheral blood cells and liver function tests, were within normal limits. Radiography of the chest and vertebral column, as well as abdominal sonography, were normal. The patient could not recall a past history of herpes zoster, hepatitis $\mathrm{B}$ or $\mathrm{C}$ infections. Laboratory investigations revealed normal full blood count, erythrocyte sedimentation rate, urea, electrolytes, glucose and liver function tests. The autoantibody screen and the serology for hepatitis $\mathrm{C}$ and $\mathrm{B}$ virus were negative.

A skin biopsy was taken from the violaceous papule on the dorsum of her right foot. The histological findings showed hyperkeratosis, parakeratosis and atrophy of the epidermis with liquefication degeneration of the basal cells (Fig. 2). A perivascular lymphohistiocytic infiltration and pigmentary incontinence in the dermis were also noted. Based on clinical and histopathologic findings, we diagnosed this case as unilateral linear. LPP. Topical treatment with betamethasone ointment was initiated, nevertheless, at 1 month of follow-up there was scant improvement of the symptoms. So, the patient was treated orally with $15 \mathrm{mg}$ prednisone daily for 2 weeks. The papules on the right side of her extremities subsided, but the hyperpigmented streak below the lower lip line remained unchanged, which later underwent progressive regression following application of arbutin cream for another month.

\section{DISCUSSION}

LPP has been described as a condition of unknown etiology which clinically differs from classical lichen planus by exhibiting dark brown macules and/or papules and a longer clinical course without pruritus or scalp, nail or mucosal involvement. LPP is most common on sun-exposed areas such as the face, neck, and flexural folds including the 
(a)

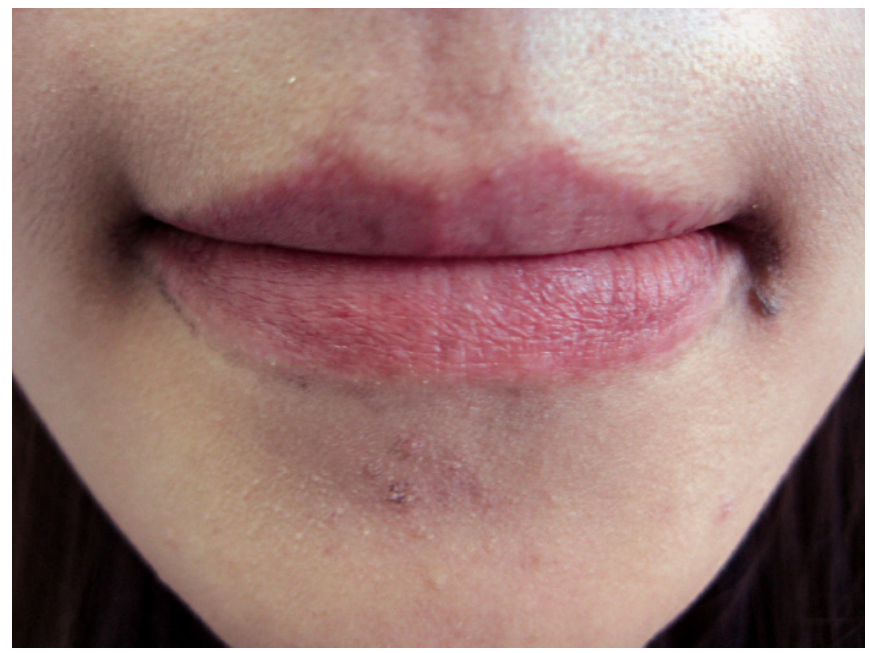

(b)

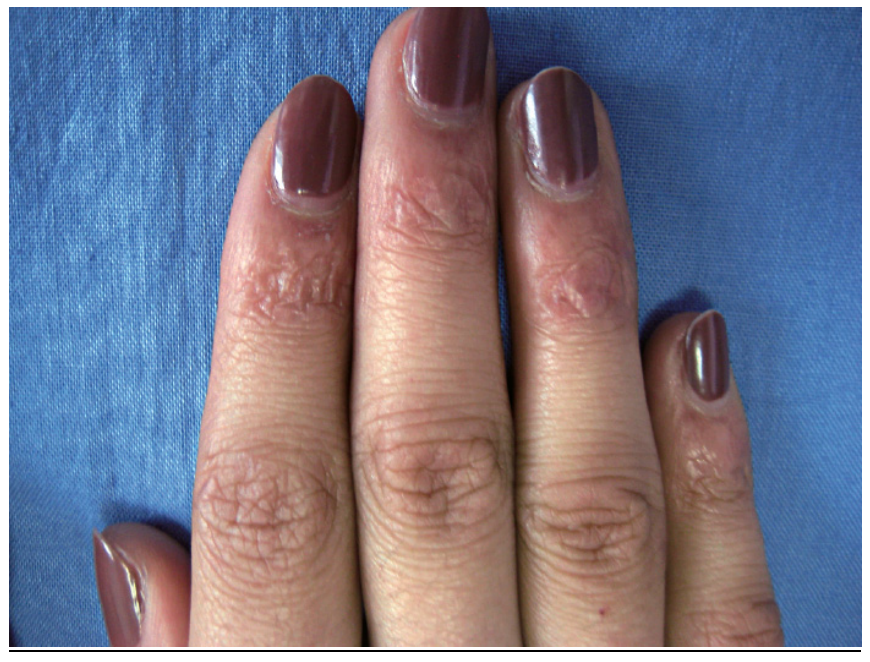

(c)

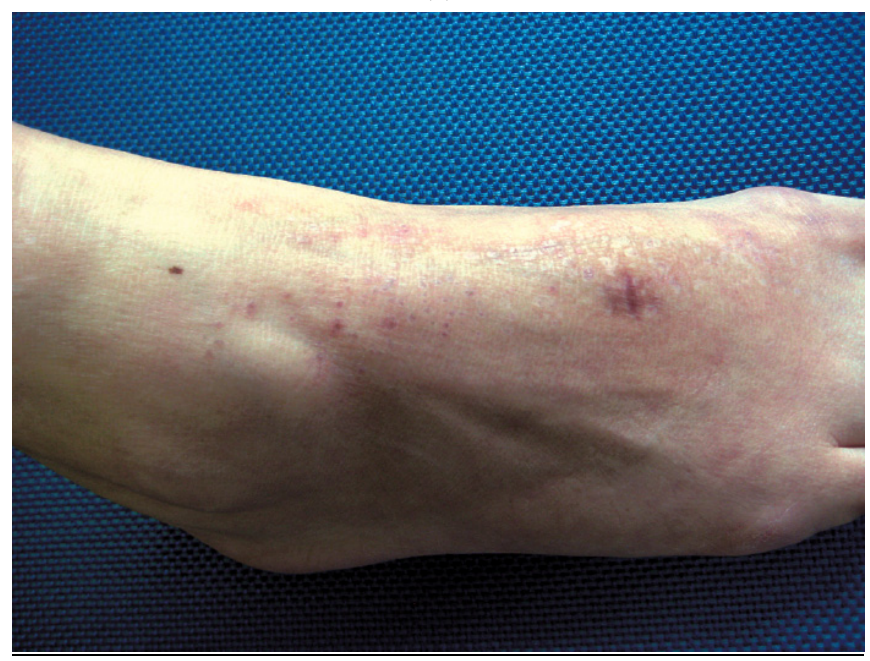

Fig. (1). The appearance and distribution of the lesions. a: A welldefined dark brown streak paralleling the right lower lip line, starting on the right angle of the mouth and ending close to the midline of the lip. b: A few dark porphyreous speckles clustered on the skin near the onychorrhiza of the fingers of the right hand, except the thumb. c: Many planar, purple and polygonal papules, the size of a millet, show a distribution in a zosteriform pattern. (a)

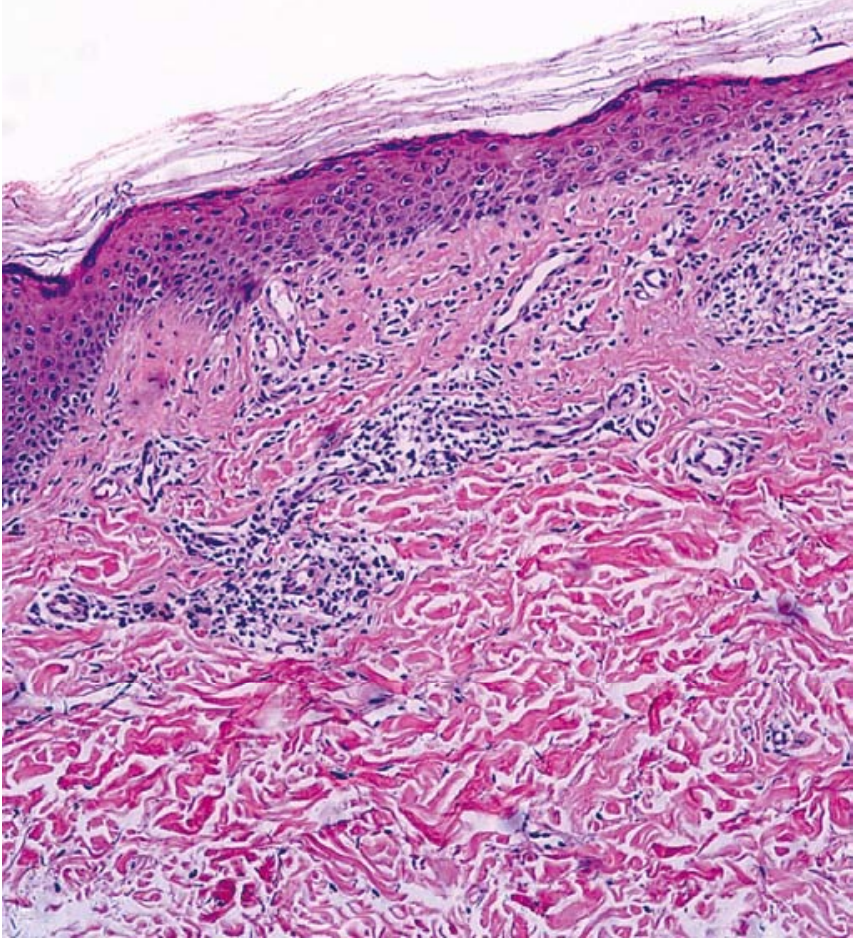

(b)

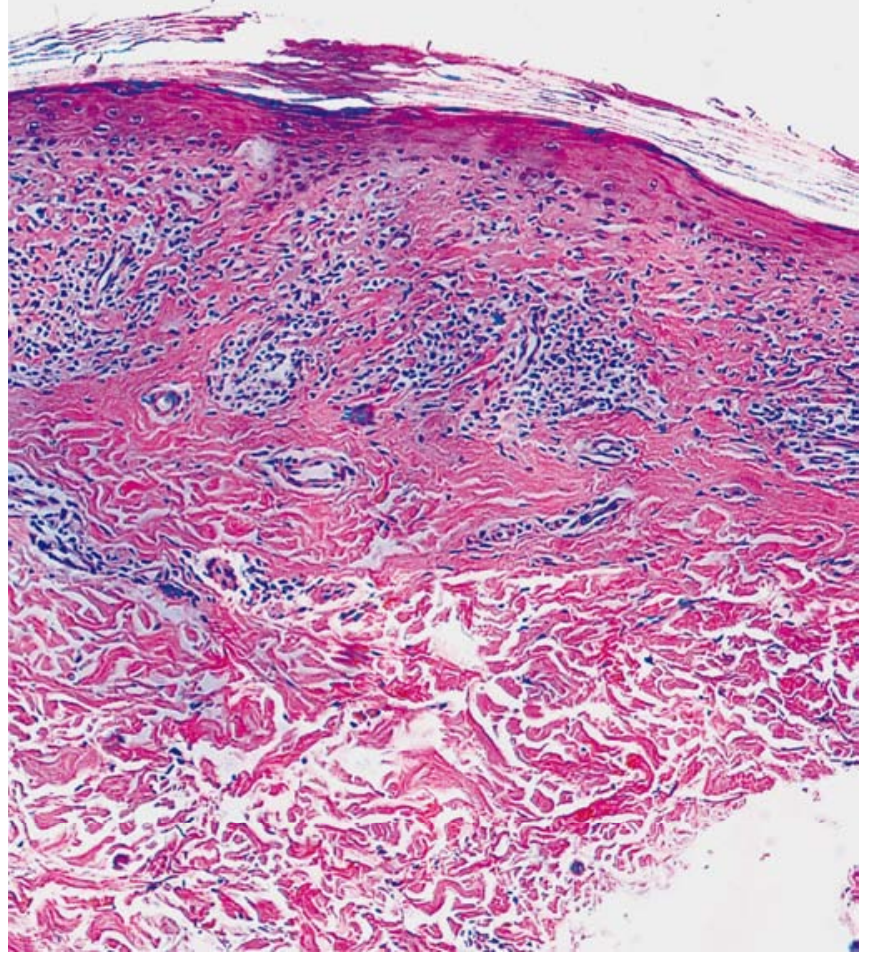

Fig. (2). (a, b). Hyperkeratosis, parakeratosis and atrophy of the epidermis with liquescent degeneration of the basal cells. A perivascular lymphohistiocytic infiltration and pigmentary incontinence in the dermis are also noted (hematoxylin-eosin stain, original magnification $\times 200$ ) . 
axilla, inguinal and submammary regions [7]. Less common presentations include a zosteriform pattern on the trunk and involvement of non sun-exposed areas such as the thigh [8, 9]. In the Korean dermatologic literature, Hong and colleagues reported two cases of LPP presenting with a linear pattern on the extremities [4]. They presumed that the linearity of the lesions was probably related to Blaschko's lines, which suggests that the predisposition to develop LPP might be determined during embryogenesis. Ji et al. also described a case of LPP along the lines of Blaschkos. Recently, Seo et al. reported a 60-year-old man who had lesions on his neck and chin with a linear pattern [6].

Our subject is a 25-year-old Chinese female whose lesions present a unilateral and linear distribution, but did not take the precise course of dermatomal lines or Blashko's lines. The lesions on the skin close to the side of the nail bed displayed the typical appearance of lichen planus, namely, presenting as scattered amethystine papules. However, similar papules on the dorsum of her right foot lined up and formed a zosteriform pattern. The histopathologic findings of a papule biopsied from this site showed hyperkeratosis, atrophic epidermis with liquefication degeneration of basal cells, and a few lymphohistiocytes in the dermis with pigmentary incontinence and the presence of melanophages. From the clinical features and the biopsy tissue image, this was diagnosed as LPP.

The most interesting feature in our subject was the brownish-black streak parallel to and near the lower lip line, which was more obvious at the right angle of the mouth. A close-up view showed that the streak consisted of some dark brown blotches, and was not an evenly pigmented line. Such a distribution of LPP had not been described previously.

The etiology of LPP is not clear. No definite precipitating factors could be identified in any of the patients with LPP. Fragrances present in commercially available preparations could possibly precipitate LPP [10]. Considering this and the fact that sun-exposed sites are frequently the first to be involved, sunlight probably plays a role in inciting LPP [10]. Our patient usually applied lip pomade on her lips and nail polish on her finger and toe nails. Moreover, the lesions occurred at sun-exposed sites. Therefore, we presume that fragrances present in the lip pomade and nail polish along with sunlight may be causative factors of these lesions. Interestingly, no lesions were found on the left side of her body or on mucosal surfaces. Further studies are required to ascertain the etiological factors of unilateral linear LPP.

The differential diagnosis of our case includes adult blaschkitis and inflammatory linear verrucous epidermal naevus (ILVEN). Blaschkitis, namely Blaschko linear acquired inflammatory skin eruption, present remitting and relapsing eruption of itchy inflammatory vesicles and papules which occurs usually on the trunk in adults [11]. The histology is more eczematous (spongiotic) than lichenoid. Blaschkitis should perhaps be regarded as a description rather than a diagnosis, a useful category for many of the disorders in this section, pending more precise identification. ILVEN usually present a pruritic, erythematous scaly lesion following Blaschko's lines [12]. About 75\% of ILVENs appear during the first 5 years of life, most often in the first 6 months. The lesions are characterized by pruritus, which may be intense. The characteristic histology shows columns of hypergranulosis with orthokeratotic hyperkeratosis alternating with equally well-defined columns of agranulosis and parakeratotic hyperkeratosis. Based on the patient's history of chief complaint, onset age, the appearance and pathological features of the lesions, the diagnosis of linear LPP other than blaschkitis or ILVEN was established.

LPP is an uncommon variant of lichen planus, for which no effective treatment is available. In the references, Tacrolimus ointment could have a beneficial role in the treatment of LPP [13]. The treatment of facial LPP includes removal of aggravating factor, vigorous photoprotection [14], and some form of active pigment reduction. Topical agents include hydroquinone, which is the most commonly used agent, often in combination with retinoic acid, corticosteroids, azelaic acid, kojic acid, and glycolic acid. Our patient initially accepted betamethasone ointment, and got scant improvement of the symptoms at 1 month of follow-up. Then, she treated orally with $15 \mathrm{mg}$ prednisone daily for 2 weeks. The papules on her extremities subsided, but the hyperpigmented streak below the lower lip line remained unchanged. After application of arbutin cream for another month, the hyperpigmented streak progressively resolved.

\section{ACKNOWLEDGEMENTS}

The authors are very grateful to Professor V. J. Hearing, Laboratory of Cell Biology, National Cancer Institute, Bethesda, MD, USA, for English-language element of this paper.

\section{CONFLICT OF INTEREST}

Declared none.

\section{REFERENCES}

[1] Bhutani L, Bedi T, Pandhi R. Lichen planus pigmentosus. Dermatologica 1974; 149: 43-50.

[2] Akagi A, Ohnishi Y, Tajima S, Ishibashi A. Linear hyperpigmentation with extensive epidermal apoptosis: a variant of linear lichen planus pigmentosus? J Am Acad Dermatol 2004; 50: S78-80.

[3] Park HJ, Lee YS. A case of multiple linear lichen planus along the lines of Blaschko. Korean J Dermatol 2006; 44: 627-9.

[4] Hong S, Shin JH, Kang HY. Two cases of lichen planus pigmentosus presenting with a linear pattern. J Korean Med Sci 2004; 19: 152-4.

[5] Ji JH, Park HY, Kim JH, et al. A case of lichen planus pigmentosus along the lines of Blaschko. Korean J Dermatol 2009; 47: 313-6.

[6] Seo JK, Lee HJ, Lee D, Choi JH, Sung HS. A case of linear lichen planus pigmentosus. Ann Dermatol 2010; 22: 323-5.

[7] Vega ME, Waxtein L, Arenas R, Hojyo T, Dominguez-Soto L. Ashy dermatosis versus lichen planus pigmentosus: a controversial matter. Int J Dermatol 1992; 31: 87-8.

[8] Cho S, Whang KK. Lichen planus pigmentosus presenting in zosteriform pattern. J Dermatol 1997; 24: 193-7.

[9] Kim KJ, Bae GY, Choi JH, Sung KJ, Moon KC, Koh JK. A case of localized lichen planus pigmentosus on the thigh. J Dermatol 2002; 29: 242-3.

[10] Kanwar AJ, Dogra S, Handa S, Parsad D, Radotra BD. A study of 124 Indian patients with lichen planus pigmentosus. Clin Exp Dermatol 2003; 28: 481-5.

[11] Imhof L, Kerl K, Barysch MJ, Dummer R, French LE, Hofbauer GF. Facial blaschkitis: case and review. Dermatology 2011; 223: 13.

[12] Gon Ados S, Minelli L, Franzon PG. Case for diagnosis. Inflammatory linear verrucous epidermal nevus. An Bras Dermatol 2010; 85: 729-31.

[13] Al-Mutairi N, El-Khalawany M. Clinicopathological characteristics of lichen planus pigmentosus and its response to tacrolimus 
ointment: an open label, non-randomized, prospective study. J Eur Acad Dermatol Venereol 2010; 24: 535-40.
[14] Vachiramon V, Suchonwanit P, Thadanipon K. Bilateral linear lichen planus pigmentosus associated with Hepatitis C virus infection. Case Rep Dermatol 2010; 2: 169-72.

(c) Zhang and Zhu; Licensee Bentham Open.

This is an open access article licensed under the terms of the Creative Commons Attribution Non-Commercial License (http: //creativecommons.org/licenses/by$\mathrm{nc} / 3.0 /$ /) which permits unrestricted, non-commercial use, distribution and reproduction in any medium, provided the work is properly cited. 